\title{
Effect of Microwave Heating on the Migration of Additives From PS, PP and PET Container Into Food Simulants
}

\author{
Ruoyin Cai \\ Rochester Institute of Technology \\ rxc1864@rit.edu
}

Kereilemang Khana

Mokwena Nthoiwa

Rochester Institute of Technology

kknmet@rit.edu

\author{
Changfeng Ge \\ Rochester Institute of Technology \\ cfgmet@rit.edu
}

\begin{abstract}
The main objective of this thesis is to test three different microwaving packaging materials that are the most common material in the market, which are polystyrene (PS), polypropylene (PP), and polyethylene terephthalate (PET), migrated into four food simulant solutions. Four different simulant solutions were used based on the food type and FDA recommendations and regulations. These food simulants include vegetable pure oil, 3\% (v/v) aqueous acetic acid, $15 \%(v / v)$ ethanol, and olive oil in the temperature of $100^{\circ} \mathrm{C}$. Headspace gas chromatography with mass spectrometric detection (GC/MS) was used to determine the relative migration values from packaging materials into food by putting the materials into contact with simulants for 10 days in temperature of $5^{\circ} \mathrm{C}$.
\end{abstract}

The analyzed results show that the migrations of food package are dependent on microwaving time, package material types and simulant types. The polystyrene (PS) caused the fastest relative migration in olive oil while the polyethylene terephthalate (PET) has the most relative migration in food simulant containing $15 \%$ ethanol.

In addition, acetaldehyde, which may be hazardous to consumers, was found in both $3 \%$ aqueous acetic acid and olive oil after 10 minutes microwaving from PET.

Key Words: migration; food additives; microwaving packaging; food simulant 


\section{INTRODUCTION}

Migration has become a major factor in regulations regarding the safety and quality of packaged food. The degree of migration is determined by various factors including the properties of real food, cooking temperature and power, chemical nature of substances in polymer and food simulants. There are three different microwave container applications, which are microwave susceptor packaging, dual-oven trays and microwavable containers.

In the USA, the Food and Drug Administration (FDA) regulate packaging materials for food contact. Both the FDAregulations and the European Community (EC) have complex regulations to control potentially harmful migrating substances from food packaging materials. However, there are no specific requirements for microwave foodcontact containers. Therefore, there is guidance on plastic containers used in the microwave cooking, in the form of recommendations on chemistry information. Companies need to check compliance of this guidance with considerable amount of migration testing for their products.

Based on these regulations above, the aim of this paper is to review critically the existing procedures about migration modeling first, and then analyze the effect of plastic type in combination with four different types of food simulants to gain more knowledge on unpredictable migration behaviors during high temperature conditions for consumer. Two methods from the Food and Drug Administration (FDA) and European Union (EU) regulations are used to evaluate the possible new compounds may be found due to degradation of the additives or polymers during the microwave heating. The objectives of this paper is as followings:
1. To comprehensively and quantitatively investigate the percentage of migration from polymer food packaging during microwave heating at different time span and temperature.

2. To evaluate the possible new compounds may be found due to degradation of the additives or polymers during the microwave heating.

In general, food-packaging interactions can be divided into three groups: migration, which is the transfer of packaging components into food; sorption, which is the transfer of food components to the packaging; and permeation, which is the transfer of components through the packaging in either direction(Ahvenainen, 2003). The process of migration of additives from microwave packaging material to food may be separated into three states: diffusion within the polymer, solution at the polymer-food interface, and dispersion into bulk food. To get better result of migration, the test should use three aqueous-based food simulants and higher cooking temperature than normal direction on the package since real food is too difficult to analyze (Risch, 2009).

Migration is a diffusion process subject to both kinetic and thermodynamic controls. Diffusion is the mas transfer due to random movement of molecules from regions of higher concentration to regions of lower concentration. However, diffusion rate is a function of only temperature, and is not affected by concentration. In that case, when we put frozen food in to microwave oven, the activity of the macroscopic molecular structures inside of plastic start so become higher and higher, the higher of heating temperature, the higher the flexibility of the polymer molecules and thus the higher the migration rates.

The transparent non-metal packaging materials is one of the most common materials used in 
microwave packaging (Lentz \& Crossett, 1988). In these types of packages, the microwaves penetrate the transparent material and are absorbed by the food. All plastics currently used in food packaging are transparent to microwaves. The most common plastics used in in microwave packaging are polypropylene (PP) or polyethylene terephthalate (PET) due to their high melting point (Belcher, 2006). Ahmed et al. indicated that during polymerization processing, there are thousands of possible additives added into polypropylene that could produce some unknown toxic chemicals which can be health risks (Ahmed, 1982). It is necessary to establish a link between the maximum temperature the container in contact with different food stimulants during heating or microwaving and migration of polypropylene additives since some additives are even carcinogens and have concern on endocrine disorder. Therefore, it is important that polypropylene products in the market should be designed to minimize overall migration limitation of additives during food manufacturing operations such as microwave heating.

\section{MATERIALS AND METHOD INSTRUMENTATION}

There are several analytical methods to separate the different components in a mixture prior to analyzing each component and determine migrants in the food contact materials such as microwave susceptors or in foods. The most common techniques used for routine analysis are high performance liquid chromatography coupled with fluorescence detection (HPLC/ FLD) or headspace gas chromatography with mass spectrometric detection (GC/MS). Different injectors, columns and interfaces are available to allow for the handling of different types of samples. The headspace GC/MS technique is very suitable for the volatile compound analysis and it has been used in the EU specific migration(Begley, Biles, \& Hollifield, 1991).

\begin{tabular}{|c|c|}
\hline \multicolumn{2}{|c|}{ Gas Chromatography/Mass Spectometry: Hewlett Packard 5890 Series II } \\
\hline Column & $30 \mathrm{~m}$ length $\times 0.25 \mathrm{~mm}$ ID \\
\hline $\begin{array}{ll}\text { Injector Tempera- } \\
\text { ture }\end{array}$ & $180^{\circ} \mathrm{C}$ \\
\hline $\begin{array}{l}\text { Detector Tempera- } \\
\text { ture }\end{array}$ & $180^{\circ} \mathrm{C}$ \\
\hline Carrier gas & Helium \\
\hline Oven temperature & $\begin{array}{l}70{ }^{\circ} \mathrm{C} \text { for } 5 \mathrm{~min} \text {; increasing by } 10^{\circ} \mathrm{C} / \mathrm{min} \text { to } 120^{\circ} \mathrm{C} \text { for } 2 \mathrm{~min} \text {; then by } 10^{\circ} \mathrm{C} / \\
\text { min to } 280^{\circ} \mathrm{C} \text { for } 5 \text { minutes }\end{array}$ \\
\hline Split ratio & $1: 30$ \\
\hline
\end{tabular}

Table 1 Configuration of GC/MS conditions 


\section{FDA RECOMMENDATIONS}

The FDA recommends stimulants based on the food type.

\begin{tabular}{|l|l|l|}
\hline \multicolumn{1}{|c|}{ Food Type } & \multicolumn{1}{|c|}{ Food Simulant } & \multicolumn{1}{c|}{ EW Simulant } \\
\hline Aqueous $(\mathrm{pH}>4.5)$ & $10 \%$ Ethanol & Distilled water \\
\hline Acidic $(\mathrm{pH} \leq 4.5)$ & $10 \%$ Ethanol & $3 \%$ Acetic acid \\
\hline Alcoholic & $10 \% \mathrm{a}$ or $50 \%$ Ethanol & $10 \%$ Ethanol \\
\hline Fatty & $\begin{array}{c}\text { Food oil, HB307b, or Miglyol } \\
812 \mathrm{c}\end{array}$ & Rectified olive oil \\
\hline
\end{tabular}

Table 2 FDA and EU recommended food simulants

a $10 \%$ ethanol can be used for foods up to $15 \%$ alcohol content.

$b$ A mixture of synthetic triglycerides, primarily C10, C12, and C14.

$c$ A fractionated coconut oil.

Generally, there are three specified food simulant solutions can be used in the experiment based on the federal applicable regulations(Garde, Catala, Gavara, \& Hernandez, 2001). These simulants are water, n-heptane, and $8 \%$ ethanol. And FDA also allows the use of other several different simulants as alternative food simulant for evaluating migration test are shown in Table 3:

\begin{tabular}{|c|c|}
\hline & \multicolumn{1}{|c|}{ Stimulant Type } \\
\hline Stimuant A & \multicolumn{1}{|c|}{ Water for aqueous foods } \\
\hline Simulant B & $\begin{array}{c}3 \% \mathrm{w} / \mathrm{v} \text { acetic acid for acidic } \\
\text { foods }\end{array}$ \\
\hline Simulant C & $\begin{array}{l}15 \% \mathrm{v} / \mathrm{v} \text { ethanol for alcohol- } \\
\text { ic products }\end{array}$ \\
\hline Simulant D & $\begin{array}{c}\text { Rectified olive oil for fatty/ } \\
\text { oily foods (n-heptane) }\end{array}$ \\
\hline
\end{tabular}

Table 3 Alternative food simulants

\section{SAMPLE SELECTED}

Foodsimulant:BasedonFDArecommendations, four different simulant solutions (vegetable oil, 3\% aqueous acetic acid, 15\% ethanol, and olive oil) were used in the experiment as shown in Figure 2. The vegetable oil and olive oil stands for fatty or oil food with processed meat; $3 \% \mathrm{w} / \mathrm{v}$ acetic acid for acidic foods like fresh vegetable; and $15 \% \mathrm{v} / \mathrm{v}$ ethanol for alcoholic products.

Microwave food-packaging material: Four most common polymer materials purchased from

local market to be used for food packaging are sampled and selected for the experiment in Figure 9. In order to accurately assess the samples, clean and empty cup of each product are obtained from their corresponding traders. Mean thickness of PS, PP and PET is $1.7 \mathrm{~mm}, 1.2 \mathrm{~mm}$ and $0.5 \mathrm{~mm}$ with non- transparent. Both PS and PP are white with non-transparent and PET is commercial black non-transparent trays, shown in Figure 3. 


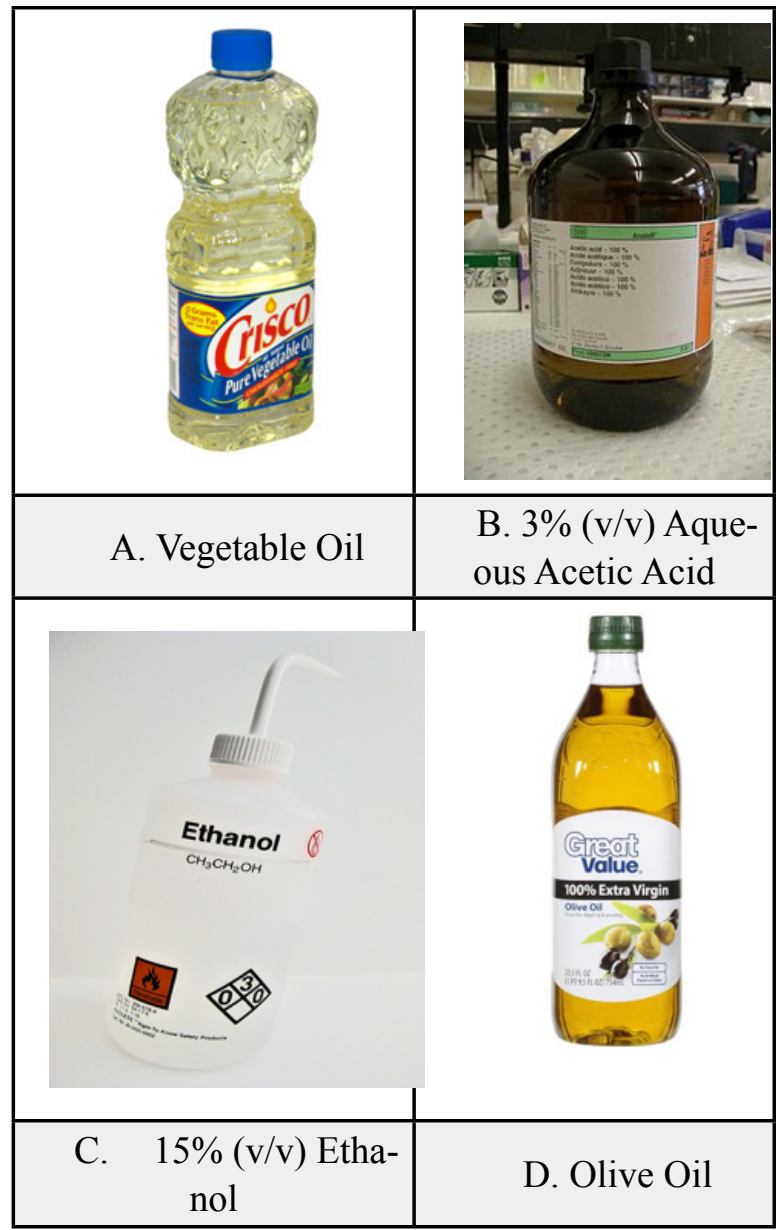

Figure 2 Four-food simulant solutions

\section{MIGRATION TESTING METHOD AND ANALYSIS}

Firstly, cut $5 \mathrm{~mm} \times 5 \mathrm{~mm}$ of the plastic material and put them into sealed vials of $7 \mathrm{~cm}^{3}$ by $4 \mathrm{~cm}^{3}$ of $15 \mathrm{ml}$ food simulant solution in Figure 4 . The simulation of package-food contact during storage prior to microwaving was carried out under the circumstances of European Commission Directive 93/8/EEC. Store all the samples in the refrigerator for 10 days in temperature of $5^{\circ} \mathrm{C}$.

1. Quantification of sample vials

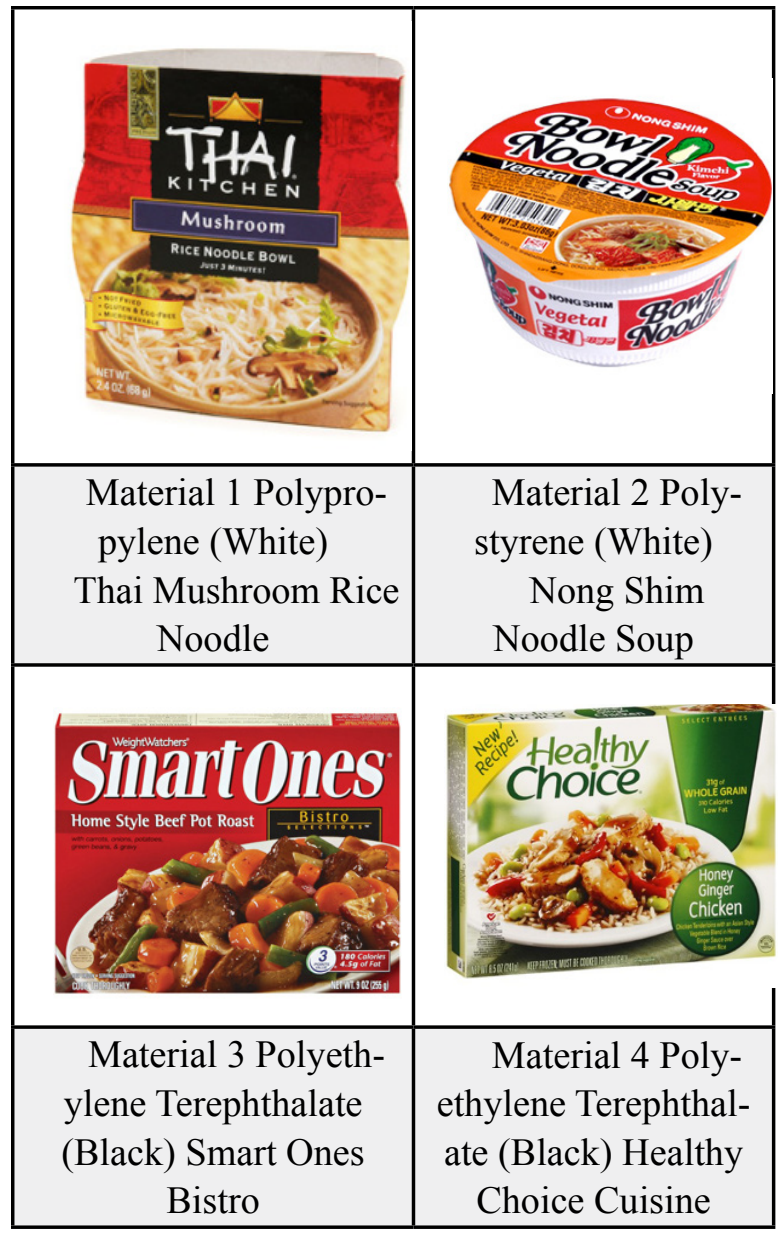

Figure 3 Four most common polymer material; in the market

After 10-day storage in the refrigerator in temperature of $5^{\circ} \mathrm{C}$, all the samples were microwaved. Output power of the oven was 540 $\mathrm{W}$, and it was determined according to ASTM F-1317-90 that is the standard test method for calibration of microwave ovens. For each combination of package/solution, 5 microwaving duration spans, ranging from 0 to 10 minutes, were applied. A total of 96 samples were tested for total migration. To avoid overheating of the seals, single exposure took 30 s followed with intensive cooling of vials in iced water. Number of these cycles was depending on cumulative exposure time required. 


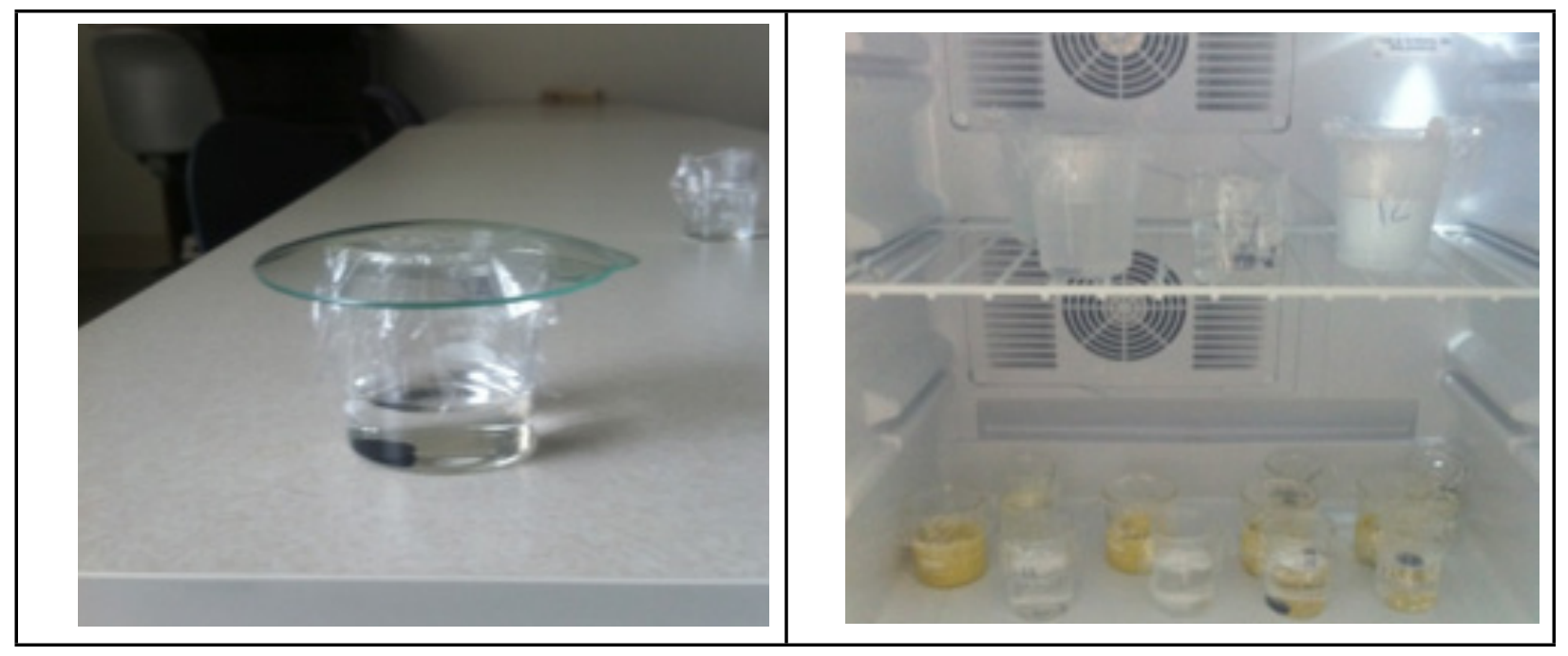

Figure 4 Samples in the experiment.

\begin{tabular}{|l|l|}
\hline Number of sample materials & $\mathbf{4}$ \\
\hline Number of food simulants & 4 \\
\hline Number of microwaving spans & 6 \\
\hline Total number of experiments & 96 \\
\hline
\end{tabular}

Table 4 List of performed experiment

An extract of food simulant (1-2ml) was transferred to a respective $10 \mathrm{ml}$ of glass vial after 10-day storage, and the vial was closed with a silicone stopper and enclosed with an aluminum crimp. The samples used to develop methods for testing was evaporated under a stream of helium at room temperature to a volume of $20 \mathrm{ml}$ and analyzed by headspace GC-MS.

\section{RESULTS AND DISCUSSION}

\section{RELATIVE MIGRATION}

Relative migration addresses that the ratio of actual migration level to the beginning 0 values obtained just after storage $=100 \%$. Table 5-8 shows the original data from GC/MS.
Based on the Figure 5-9 of the thesis, the $\mathrm{x}$-axis is the cumulative microwaving time from 0 to 10 minutes with 2-minute step. The y-axis is the relative migration. Here we compared the results based on four different materials, PP, PS, and two types of PET, which are indicated with different color. At the beginning 0 minute, because the microwave is not operated, there is no migration, and the simulant is $100 \%$ food simulants. When the microwave begins to be operated with longer time, the migrations from these four different plastics are also increased accordingly, especially after the 4-minute period. It is shown that these four different materials present different behavior, but these curves have similar trend.

As shown in Figure 5 and 6, PP presents most dramatic change compared to the other three materials. However, when the materials are immersed in ethanol and olive oil, the PS and PET present much higher migration compared to the other two materials, and PP presents relatively better behavior in this case. The most dramatic rise of migration is carried out from white polystyrene cup into olive oil (Figure 8), as 
cumulative exposure time extended 10 minutes.

Relative migration values in olive oil reach level of $167 \%$ in comparison with initial samples in the previous 8 minutes.

\begin{tabular}{|c|c|c|c|c|}
\hline $\begin{array}{c}\text { Microwaving } \\
\text { Time } \\
\text { (Minute) }\end{array}$ & $\begin{array}{c}\text { Percent of } \\
\text { Material 1 }\end{array}$ & $\begin{array}{c}\text { Percent of } \\
\text { Material 2 }\end{array}$ & $\begin{array}{c}\text { Percent of } \\
\text { Material 3 }\end{array}$ & $\begin{array}{c}\text { Percent of } \\
\text { Material 4 }\end{array}$ \\
\hline 0 & 100 & 83.2 & 88.88 & 89.01 \\
\hline 2 & 88.9 & 83.8 & 84.71 & 88.05 \\
\hline 4 & 100 & 82.95 & 85.1 & 88.13 \\
\hline 6 & 100 & 87.11 & 85.64 & 88.77 \\
\hline 8 & 89.53 & 80.7 & 92.94 & 96.62 \\
\hline 10 & 77 & 76.2 & 82.81 & 87.42 \\
\hline
\end{tabular}

Table 5 GC/MS results in food simulant A (vegetable oil)

\begin{tabular}{|c|c|c|c|c|}
\hline $\begin{array}{c}\text { Microwaving } \\
\text { Time } \\
\text { (Minute) }\end{array}$ & $\begin{array}{c}\text { Percent of } \\
\text { Material 1 }\end{array}$ & $\begin{array}{c}\text { Percent of } \\
\text { Material 2 }\end{array}$ & $\begin{array}{c}\text { Percent of } \\
\text { Material 3 }\end{array}$ & $\begin{array}{c}\text { Percent of } \\
\text { Material 4 }\end{array}$ \\
\hline 0 & 23.51 & 19.9 & 14.15 & 17.54 \\
\hline 2 & 11.39 & 16.4 & 13.77 & 16.45 \\
\hline 4 & 12.49 & 12.12 & 11.36 & 18.07 \\
\hline 6 & 13.95 & 9.37 & 11.32 & 11.63 \\
\hline 8 & 8.41 & 10.67 & 9.91 & 10.24 \\
\hline 10 & 6.98 & 10.37 & 3.76 & 8.43 \\
\hline
\end{tabular}

Table 6 GC/MS results in food simulant B (3\% aqueous acetic acid)

\begin{tabular}{|c|c|c|c|c|}
\hline $\begin{array}{c}\text { Microwaving } \\
\text { Time } \\
\text { (Minute) }\end{array}$ & $\begin{array}{c}\text { Percent of } \\
\text { Material 1 }\end{array}$ & $\begin{array}{c}\text { Percent of } \\
\text { Material 2 }\end{array}$ & $\begin{array}{c}\text { Percent of } \\
\text { Material 3 }\end{array}$ & $\begin{array}{c}\text { Percent of } \\
\text { Material 4 }\end{array}$ \\
\hline 0 & 79.82 & 65.54 & 81.94 & 77.66 \\
\hline 2 & 76.47 & 58.58 & 81.39 & 79.01 \\
\hline 4 & 43.33 & 34.37 & 34.75 & 48.59 \\
\hline 6 & 37.19 & 42.98 & 20.29 & 40.78 \\
\hline 8 & 36.67 & 13.74 & 29.22 & 28.43 \\
\hline 10 & 27.67 & 6.27 & 10.47 & 55.46 \\
\hline
\end{tabular}

Table 7 GC/MS results in food simulant C (15\% ethanol) 


\begin{tabular}{|c|c|c|c|c|}
\hline $\begin{array}{c}\text { Microwaving } \\
\text { Time } \\
\text { (Minute) }\end{array}$ & $\begin{array}{c}\text { Percent of } \\
\text { Material 1 }\end{array}$ & $\begin{array}{c}\text { Percent of } \\
\text { Material 2 }\end{array}$ & $\begin{array}{c}\text { Percent of } \\
\text { Material 3 }\end{array}$ & $\begin{array}{c}\text { Percent of } \\
\text { Material 4 }\end{array}$ \\
\hline 0 & 100.82 & 100 & 97.44 & 72.08 \\
\hline 2 & 100 & 98.3 & 100 & 77.88 \\
\hline 4 & 100.16 & 100 & 100 & 75.02 \\
\hline 6 & 94.64 & 98.07 & 100 & 49.7 \\
\hline 8 & 100.7 & 98.78 & 100 & 11.14 \\
\hline 10 & 109.11 & 31.51 & 100 & 4.85 \\
\hline
\end{tabular}

Table 8 GC/MS results in food simulant D (olive oil)

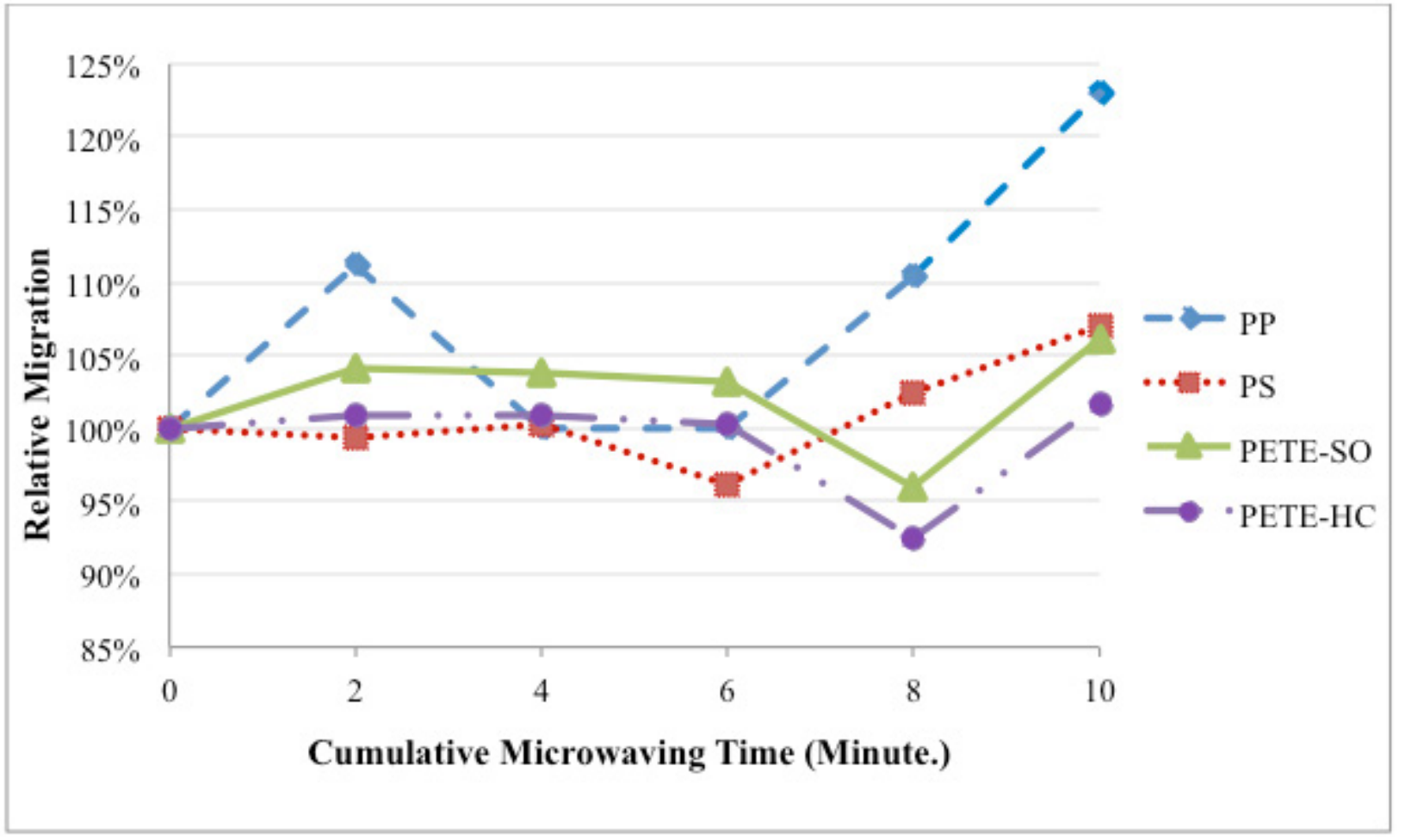

Figure 5 Relative migration values from four containers into food simulant A as a function of microwaving time. 


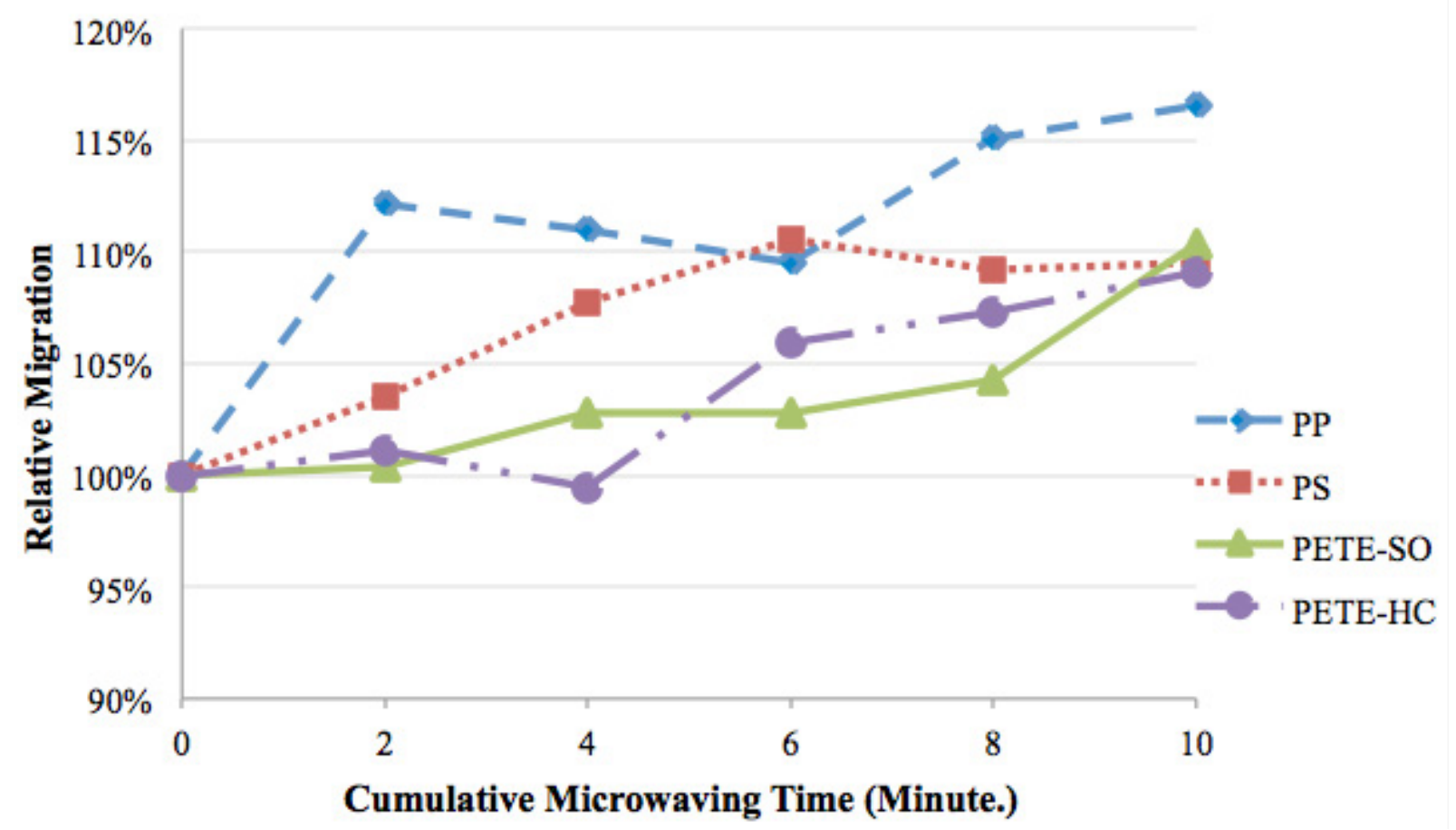

Figure 6 Relative migration values from four containers into food simulant B as a function of microwaving time.

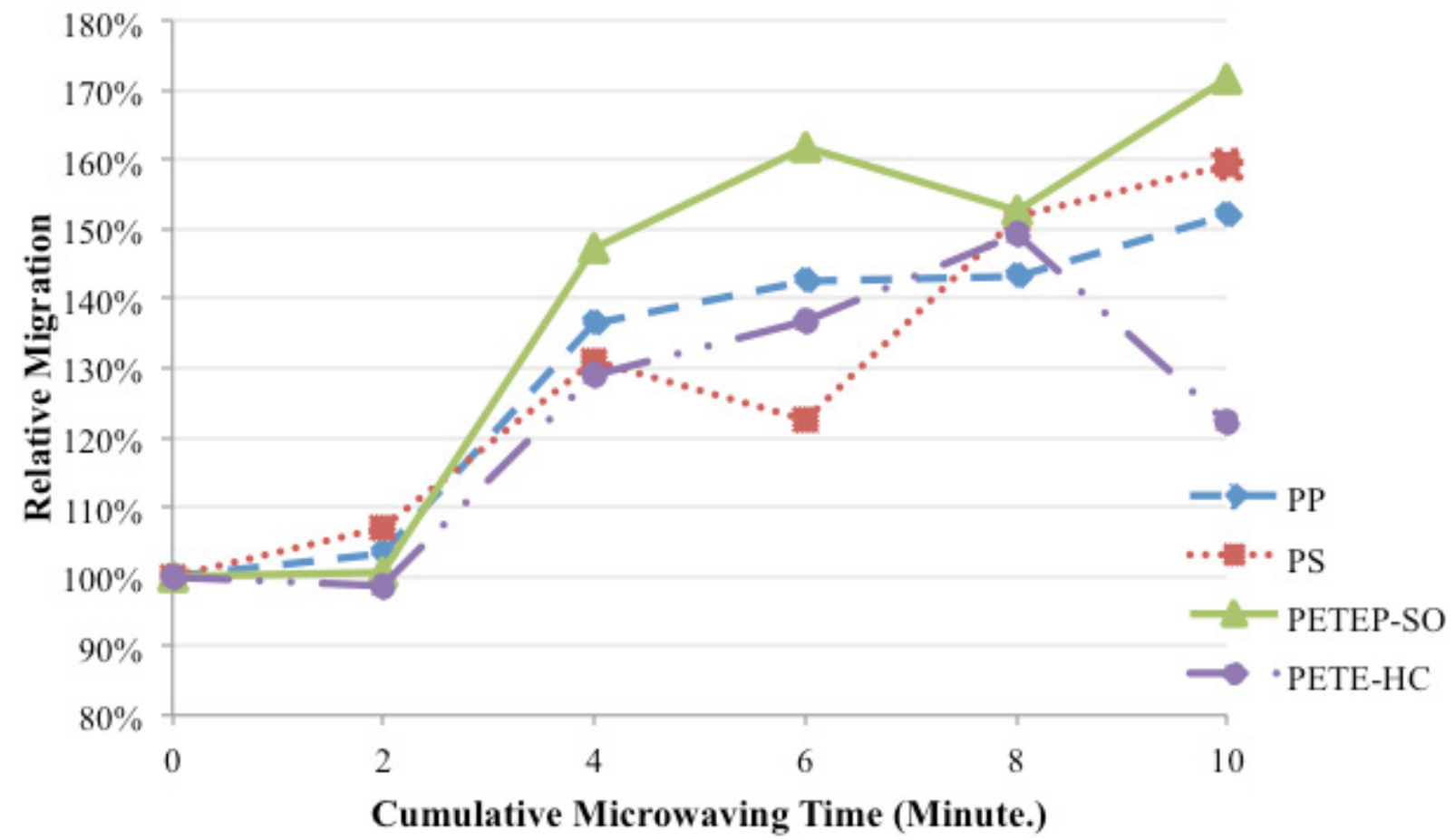

Figure 7 Relative migration values from four containers into food simulant $C$ as a function of microwaving time.. 


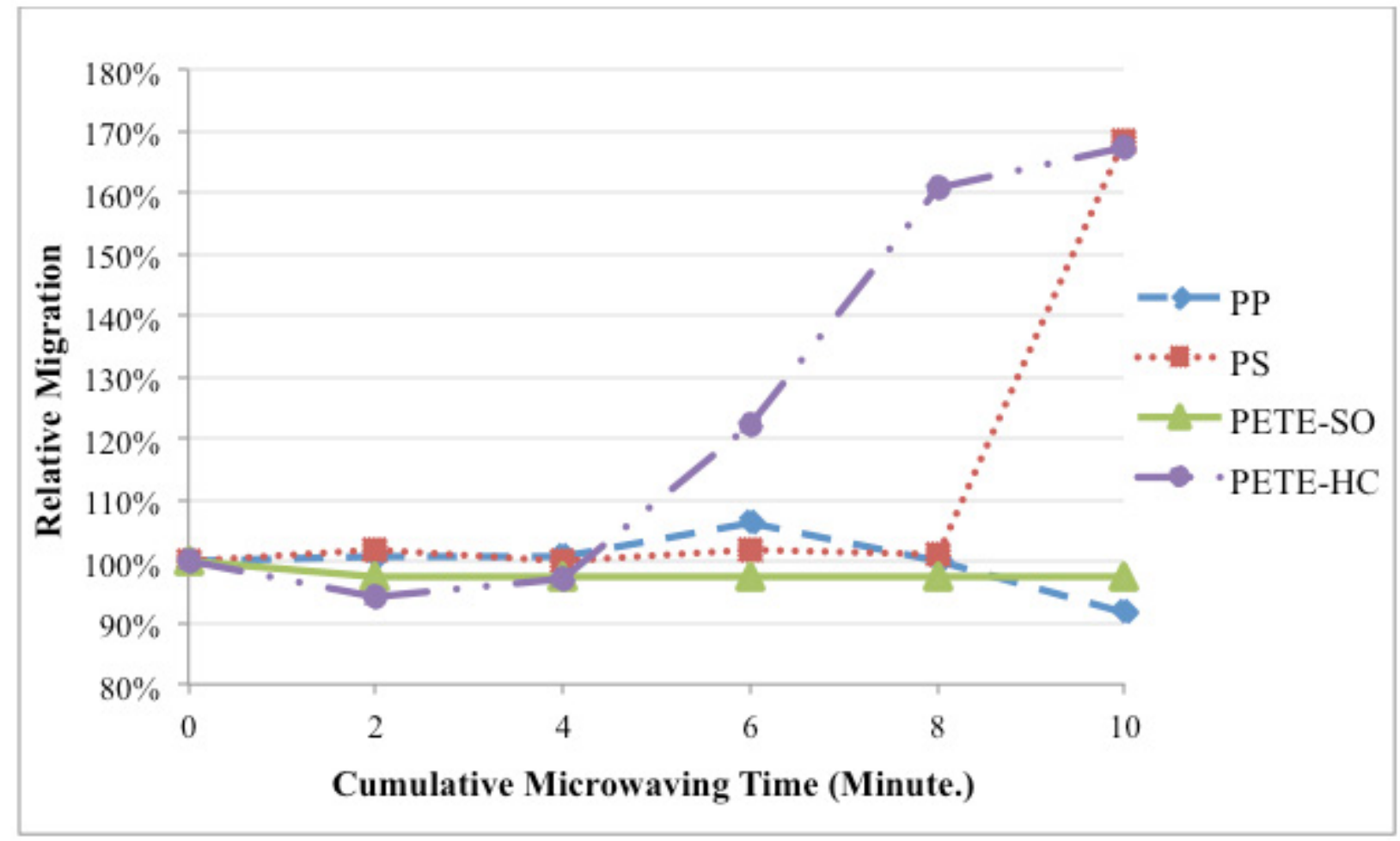

Figure 8 Relative migration values from four containers into food simulant $D$ as a function of microwaving time.

The curves of relative migration of four different polymer materials as function of cumulative microwaving time are shown in Figures 5-9.
The results are further analyzed by comparing the results when the microwave was operated after $10 \mathrm{~min}$. The migrations of the four different materials in each simulant are averaged, and the

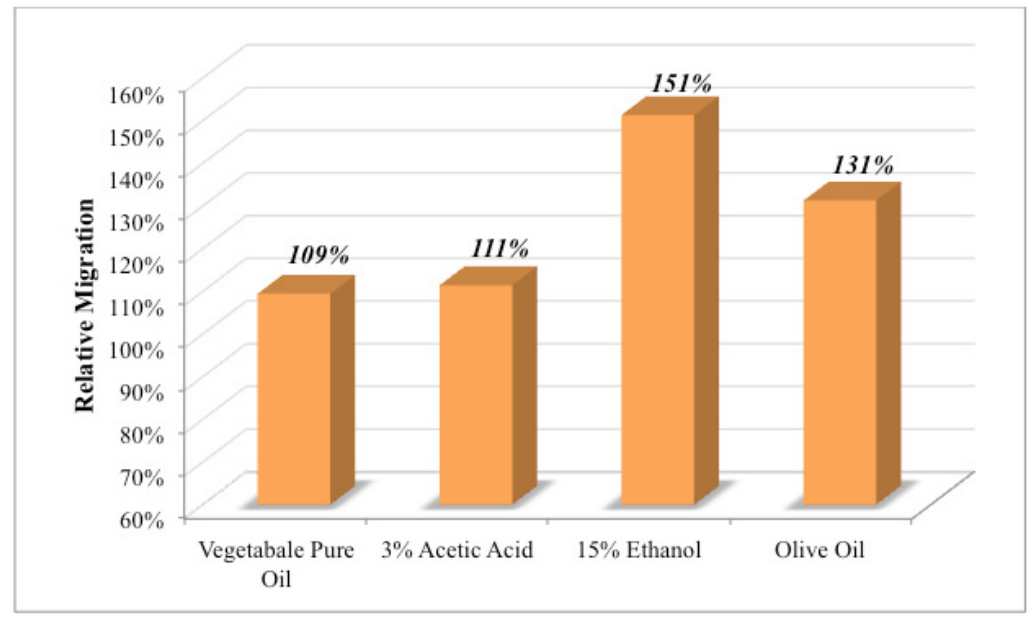

Figure 9 Average of four total relative migration values after microwaving for 10 minutes into four food simulants 


\begin{tabular}{|c|c|c|c|c|}
\hline \multirow{2}{*}{$\begin{array}{c}\text { Microwaving } \\
\text { Time } \\
\text { (Minute) }\end{array}$} & \multicolumn{4}{|c|}{ Food Simulant } \\
\cline { 2 - 5 } & $\begin{array}{c}\text { Vegetable pure } \\
\text { oil }\end{array}$ & $\begin{array}{c}3 \% \text { aqueous acetic } \\
\text { acid }\end{array}$ & $15 \%$ ethanol & Olive oil \\
\hline 0 & $\mathrm{~N}$ & $\mathrm{~N}$ & $\mathrm{~N}$ & $\mathrm{~N}$ \\
\hline 2 & $\mathrm{~N}$ & $\mathrm{Y}$ & $\mathrm{N}$ & $\mathrm{N}$ \\
\hline 4 & $\mathrm{~N}$ & $\mathrm{~N}$ & $\mathrm{~N}$ & $\mathrm{~N}$ \\
\hline 6 & $\mathrm{~N}$ & $\mathrm{~N}$ & $\mathrm{~N}$ & $\mathrm{Y}$ \\
\hline 8 & $\mathrm{~N}$ & $\mathrm{Y}$ & $\mathrm{N}$ & $\mathrm{Y}$ \\
\hline 10 & $\mathrm{~N}$ & $\mathrm{Y}$ & $\mathrm{N}$ & $\mathrm{Y}$ \\
\hline
\end{tabular}

Table 9 Migration of substance result from PET

results are compared in this Figure 9. It can be seen that different simulants present different amount of averaged migration. It is shown that the vegetable pure oil and acetic acid generate relative less migration, while $15 \%$ ethanol results in the most migration in Figure 9.

\section{MIGRATION OF SUBSTANCES}

As microwaving time increases, a particular substance acetaldehyde has been found in the GCMS results on both $3 \%$ aqueous acetic acid and olive oil. During the manufacturing of synthetic PET, acetaldehyde is formed as a thermal degradation product when the temperature reaches the melting point (Nijssen, Kamperman, \& Jetten, 1996). Acetaldehyde usually occurs naturally in ripe fruits, vegetables and coffee. It can also be used as lactic acid fermentation in chees, flavoring agent in fish preservative, and alcohol fermentation in wine (Ozlem, 2008). The properties of acetaldehyde include high water solubility, distinct fruity and pleasant odor and taste. In that case, even though the PET is suitable for regulations, it is concluded that these PET microwavable containers might be raised to critical levels with increasing temperature for acetaldehyde migration and should not be superheated in microwave especially when the food has lots of acidic or fatty content.

\section{CONCLUSIONS}

We have shown the effects of microwave heating on polystyrene (PS), polypropylene (PS) and polyethylene terephthalate (PET) food packages immersed in four different food simulants with respect to the migration of chemical compounds from plastic additives. The polystyrene (PS) caused the fastest relative migration in olive oil while the polyethylene terephthalate (PET) has the most relative migration in food simulant containing 15\% ethanol. By averaging the migrations of the four different materials in each food simulant, it has been shown that the use of ethanol as a fatty food simulant during microwave heating can lead to significant migration. With the increase of microwaving time, in contact with foods simulant, acetaldehyde migration from PET package into food is more substantial. Therefore, PET bottle manufacturers must be very careful in critical control points of the process and control the acetaldehyde levels at necessary stages. And it also necessary to calibrate storage condition before microwaving, microwaving heating temperature control which is defined by different microwave output power and processing of material by each manufacturing. Those are more challenging and will be considered in our future work 


\section{REFERENCE}

[1] Ahmed, Mukhtar. (1982). Polypropylene fibers, science and technology: Elsevier Scientific Publishing Company Amsterdam.

[2] Ahvenainen, Raija. (2003). Novel Food Packanging Techniques: CRC Press.

[3] Begley, Timothy H, Biles, John E, \& Hollifield, Henry C. (1991). Migration of an epoxy adhesive compound into a food-simulating liquid and food from microwave susceptor packaging. Journal of agricultural and food chemistry, 39(11), 1944-1945. Link

[4] Belcher, JN. (2006). Industrial packaging developments for the global meat market. Meat Science, 74(1), 143-148. $\underline{\text { Link }}$

[5] Garde, JosÉ A, Catala, Ramon, Gavara, Rafael, \& Hernandez, Ruben J. (2001). Characterizing the migration of antioxidants from polypropylene into fatty food simulants. Food Additives \& Contaminants, 18(8), 750-762. Link

[6] Lentz, RR, \& Crossett, TM. (1988). Food/ susceptor interface temperatures during microwave heating. Microwave World, 9(5), 11-15.

[7] Nijssen, Ben, Kamperman, Ton, \& Jetten, Jan. (1996). Acetaldehyde in mineral water stored in polyethylene terephthalate (PET) bottles: odour threshold and quantification. Packaging Technology and Science, 9(4), 175-185. Link

[8]
[9] Risch, Sara J. (2009). Food packaging history and innovations. Journal of agricultural and food chemistry, 57(18), 8089-8092. Link

\footnotetext{
zlem, Kizilirmakesmer. (2008). Acetaldehyde migration from polyethylene terephthalate bottles into carbonated beverages in Turkiye. International Journal of Food Science and Technology, 43(2), 333. Link
} 